\title{
BRICS: Is the Group Really Creating Impact?
}

\author{
Dr. Sadaf Mustafa ${ }^{1}$, Ammad Zafar $^{2}$,Dr. Saima Akhter ${ }^{3}$ \\ ${ }^{1}$ Department of Commerce, University of Karachi, Karachi \\ ${ }^{2,3}$ Department of Public Administration, University of Karachi, Karachi
}

\begin{abstract}
In 2001, Jim O'Neill coined the acronym for Brazil, Russia, India and China as the largest emerging markets economies. He expected them to grow faster than the developed countries and to play an increasingly important role in the world. In 2009, BRIC countries held their first summit which in its 3rd summit turned into BRICS with the addition of South Africa. The BRICS now represent 3 billion people and a combined GDP of $\$ 16$ trillion. The group is the third giant after the EU and the US. Analysts predict that the BRICS will overtake US in terms of GDP this year and the G7 by 2030. In the summit in July 2014, BRICS leaders have approved creating the BRICS New Development Bank which would fund long-term investment in infrastructure and more sustainable development. The economics projections show that till 2040, the BRICS is expected to rule the world market.
\end{abstract}

Keywords- Emerging Economies, GDP, FDI, Bank, BRICS.

\section{INTRODUCTION}

Brazil, Russia, India, China and South Africa (BRICS) are leading emerging economies and political powers at the regional and international level. The acronym was originally created in 2001 to highlight the exceptional role of important emerging economies and only included Brazil, Russia, India and China as BRIC (Neill, 2001). South Africa has joined the group since the third summit of 2011 in China which made it BRICS (Piper, 2015). The BRICS now represent 3 billion people and a combined GDP of 16 trillion dollars that now shows a strong role in economy of the world (Prasad, 2015). BRICS differ in culture, area, religion but one common thing among them is their growing economy (Almeida, 2009). Each BRICS country has a distinctive economic, social and culture characteristic, except the fact that all the BRICS countries have enjoyed a high growth rate during the first decade of this century and this growth has made the group appear as a powerful force in the global economy. Russia is a commodity-driven economy due to high demand of commodities, China with its good and cheap production facilities is a powerhouse of exports, India with a large population is a domestic demand-driven economy, Brazil has much established economic structure and South Africa represents the fast-growing region of Africa. These are the factors that make BRICS countries as emerging economies. The BRICS share of the global Economy in terms of GDP grew from $11 \%$ in 1990 to $25 \%$ in 2011 . Analysts predict that the BRICS will overtake major economic leaders in the upcoming years as BRICS countries are growing really fast with China and India having the major role (Dhar, 2012).

\section{WORLD NEED THE BRICS}

There are few forums in the world that represents groups of nations like G7, OECD, and NAFTA etc. Out of them, Group of Seven (G7) has a leading role and, more broadly the Organization for Economic Cooperation and Development (OECD) but the OECD is now no longer undisputed. Most multi-lateral institutions were designed in the era when the West dominated the world in the last century. The US and Europe are over-represented in the IMF and the World Bank. Together with Japan, they control most regional development banks as well. The now BRICS countries were neither entertained well hence not fully satisfied with their memberships at G7 and OECD (Almeida, 2009). This is why BRICS summits are so important. These meetings provide a unique forum where non-OECD leaders can discuss global challenges and co-ordinate their actions within and outside global institutions. The small size of the club and the absence of OECD partners help in shaping the discussions at the summit.

\section{BRICS NEW DEVELOPMENT BANK (NDB)}

In the summit in July 2014, BRICS leaders have approved creating the BRICS New Development Bank which would fund long-term investment in infrastructure and more sustainable development in the BRICS countries and the developing countries (Jones, 2014). The BRICS bank has begun with an authorized capital contributed from its member countries amounting to $\$ 50$ billion (Biswas, 2015) The estimated unmet needs in the emerging and developing countries, in the field of infrastructure and more environmentally sustainable forms of development are around US $\$ 1$ trillion annually (Jones, 2015). They could mark a profound shift in the way global finance and politics might operate in the years ahead by funding in the emerging and developing 
economies. There is a clear case for BRICS bank to be a complement to the existing finance institution in the public and private sector to support the future growth of the developing and emerging economies. The World Bank and International Monetary Fund, formed after World War II under the Bretton Wood System, served to create a philosophical framework within which the global political economy was shaped for many decades. But the role of these institutions is no longer undisputed as they are controlled by the world market leaders as discussed above. This can provide the BRICS bank an opportunity to get a control over the countries that were previously neglected by IMF and WB due to the political influences. There also appeared some conflicts among the members during the conversion of BRICS bank from an idea to reality that mainly were due to having greater power and say in the bank matter. China with having the Headquarter seemed to be the winner but the formation has clearly showed that the South countries has realized the need to minimize the status conflict and working together to reduce the West dominance (Cooper and Farooq, 2015).

The BRICS News Development Bank is also made for the South-South cooperation and to respond to the some of the existing gaps in the financial architecture of Southern countries (Schablitzki, 2014). But still there are questions on the scope of the New Development Bank. The method of gathering capital, the capital level, the lending method and what geographical areas the bank is going to cover are still not clear. It is also questionable that how the NDB will develop cooperation with other public and private development financial institutions. The BRICS bank, like the World Bank, is expected to fund much needed physical and social infrastructure in the BRICS countries as well as other developing economies to fund the need of finance. The AIIB, a development bank like NDB is focusing in Asia so the NDB is likely to focus on development in Africa and Latin America (Jones, 2015).

\section{THE NEW LEADER AS THE NEW STAKEHOLDER}

It is clear that the high growth rate, economic potential and demographic development are putting the BRICS increasingly in a leading position in setting the global agenda and having a greater say in the global governance. (Morazan, Knoke, Knoblauch and Schafer, 2012). Since their first summit, the BRICS countries have called for a more multi-polar world order based on cooperation, coordinated action and collective decision-making of all states. Hence, they started to form a strategic alliance to reform for the $21 \mathrm{st}$ century the institutions of global governance such as the World Bank, International Monetary Fund and the United Nations Security Council that have remained unchanged from the world of 1945. The role of these institutions that was for peace and development is now disputed due to having a strong influence by USA, Japan and the European Union in decision making. The new emerging economies were dissatisfied with the role that formed BRICS, an acronym given to the group in 2001. The BRICS as a group was expected to step up their role in building better global economy and reducing influence of the current market leaders (Neill, 2001).

The level of coordination amongst the BRICS countries in setting the global agenda is still too examined in the coming years due to having conflict of interest among the member ((Cooper and Farooq, 2015). But the member of BRICS has greatly realized the need of this forum and trying to minimize the conflicts and is working on contributing widely in the changing economic scenario as well as the active participants of the changing political scenario of the world (Morazan, Knoke, Knoblauch and Schafer, 2012). The BRICS is not only focusing in developing their own economy but is also playing a major role in the development of low income countries by funding their finance need (Moghadam, 2011). This can be part of their agenda to control not only the world economy but also having an active role in the political scenario.

The table below shows the standing of BRICS in the global economy from 1991 to 2015 in terms of populations, Gross Domestic Product, exports and imports in comparison with the United States and the European Union being the market leaders and the main competitors to analyze the change in the world market during the period.

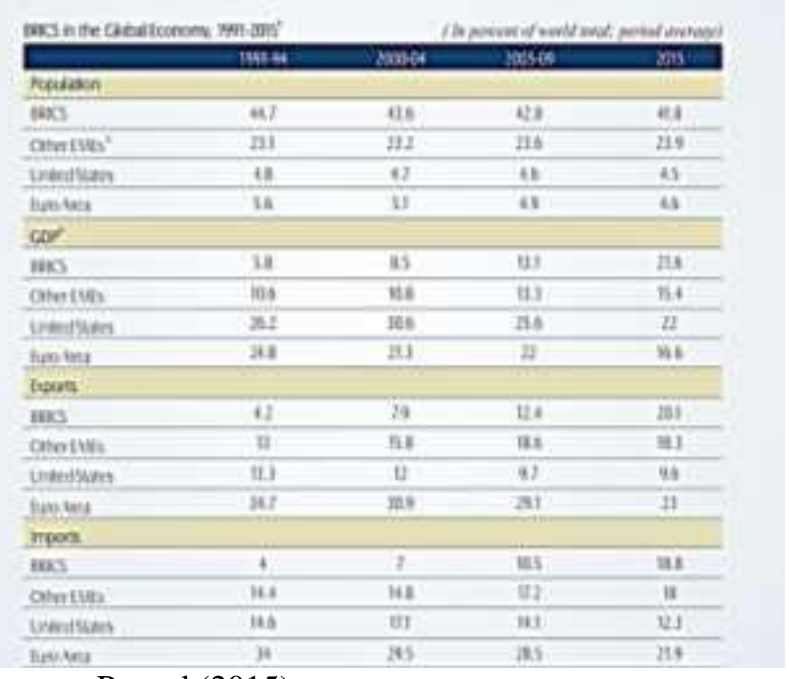

Source: Prasad (2015)

The above table can be explained by dividing it into following categories:

Populations: The BRICS shares the highest ratio of population in comparison with other emerging 
economies, USA and Euro Area. The population share of BRICS has declined since 1991 to 2015 from $44.7 \%$ to $41.8 \%$. But still the BRICS share constitutes the major of the total world population which shows the higher demand of commodities in comparison with other economic groups i.e. USA and EU.

GDP: The GDP share of the BRICS was lower than the US and EURO area in 1991 that was recorded at $5.8 \%$ which increased to $21.6 \%$ in 2015 leaving the EU behind it whose share was recorded at $16.6 \%$ in the same year. This shows that EU is now very far to reach the BRICS level again. The GDP share of USA in 2015 is recorded at $22 \%$ which is very close to the BRICS share with USA only $0.4 \%$ ahead. This difference can be covered easily by the BRICS members as they are enjoying a high economic growth. BRICS has appeared a competitor to the US GDP share.

Exports: The export share of BRICS was very low in the early 90 s recorded at $4.2 \%$ only and European Union share recorded at $34.7 \%$ had the highest share in the world exports but the BRICS share significantly increased to $20.1 \%$ till the year 2015 getting closer to the share of EU that was recorded at $23 \%$ in 2015. EU ahead of BRICS with only a difference $2.9 \%$ which is expected to cover as one of the major member of BRICS i.e. China is enjoying an export oriented economy. The share of USA is the world exports is very low than the BRICS i.e. only $9.6 \%$.

Imports: The imports of BRICS were less in the 90s which was only $4 \%$ that rise to around $19 \%$ till 2015 showing a major change. The share of imports of other economies like US and EU has declined in comparison with the 20th century. The EU shared $34 \%$ in the 90 s which now is only $21.9 \%$ and the share of US is now $12.3 \%$ which was $14.6 \%$ in 1990 s. This share of emerging BRICS economies in the imports of the world shows that the demand in these countries is moving in upward direction.

USA, European Union and Japan are considered as the current market leaders in terms of GDP, trade, foreign direct investment and market capital. But the BRICS countries are on the way to compete the current leaders. The figure below shows the projections under the head of market capital of BRICS in comparison with European Union, USA and Japan:

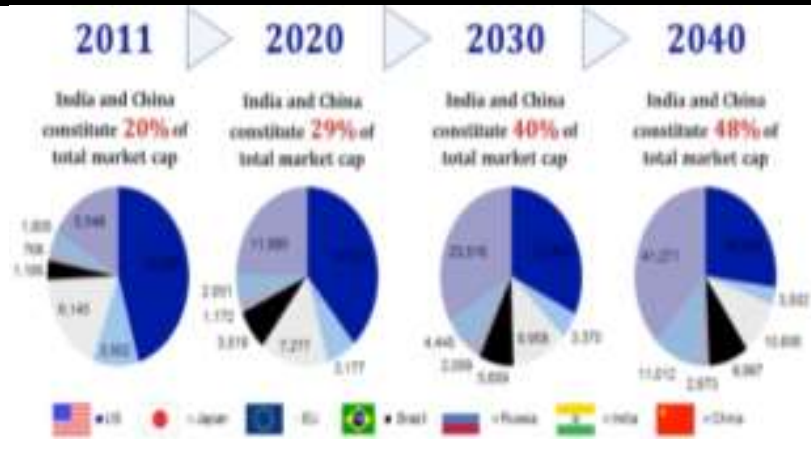

The above figure shows the past position and the projection of share of market capital of the globe emphasizing US, Japan, EU, Brazil, Russia, India and China. The position in 2011 to 2040 shows a major change. The above figure can be interpreted as more than $70 \%$ of the total market capital of the world in 2011 was held by United States, Japan and European Union while the BRICS countries excluding South Africa only had around $25 \%$ share in the world market capital. The share of US, EU and Japan is expected to decline by approximately $15 \%$ by $2020,20 \%$ by 2030 and $30 \%$ in 2040 while the share of BRICS countries would increase to around $70 \%$ in 2040 . The $48 \%$ of the market capital share would be only held by India and China by 2040 . This means that till 2040, BRICS is expected to rule the world market by having the greatest share in the market capital. Among the BRICS member, China and India will appear as the new stakeholders of the economy leaving the current market leaders United States, Japan and European Union behind them. China in terms of GDP has already appeared as the largest economy in 2015 leaving USA behind it.

\section{FDI IN BRICS COUNTRIES}

The diagram below shows the position of inflow of foreign direct investment in the BRICS countries in comparison with other global economics groups including G20, APEC, NAFTA, ASEAN and MERCOSUR in 2013 as well as in the pre-economic crisis period of 2007. This diagram can analyze the interest of investors in the economic groups after the economic crisis to further know the impact of BRICS in the global economy 
pecifically.

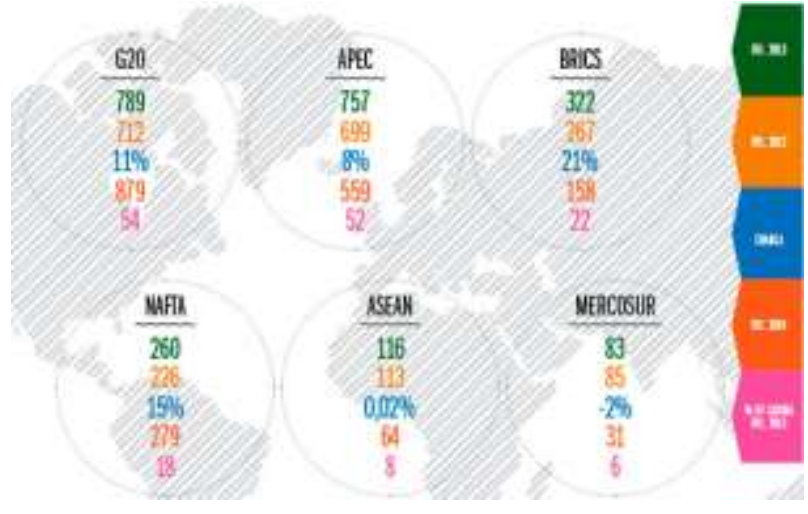

Source: World Organization for Development (2014)

The above diagram shows the interest of investors in different economic groups before and after the economic crisis of 2007. The diagram can be explained as that in 2013, the BRICS received more than $22 \%$ of total FDI globally. In 2007 , it received $\$ 158$ billion and its receipt in 2013 is twice as much as in pre-crisis years. This group of countries has thus shown that they are still of interest to investors and are cooperating to develop investment activity. $\$ 322$ billion was invested in these five countries, which is $21 \%$ higher than a year earlier which was recorded at $\$ 267$ billion. G20 and APEC still have a larger share in the world FDI amounting to $\$ 789$ billion and $\$ 757$ billion respectively but the BRICS has shown a noticeable growth. The BRICS has crossed NAFTA, ASEAN and MERCOSUR in FDI. NAFTA's share has increased by $15 \%$ in 2013 in comparison with 2012 but ASEAN and MERCOSUR shares have decreased. It is expected that due to their good performance in the economy of the world, the FDI is likely going to gradually shift from OECD to BRICS countries in the coming years (Morazan, Knoke, Knoblauch and Schafer, 2012).

\section{CONCLUSION}

The research paper finds that the BRICS appeared as the major influencer in the global economy. The BRICS whose members are Brazil, Russia, India, China and South Africa are now the main brick of the economic foundation of the world. The BRICS members have distinctive qualitative characteristics but the common thing among them is their economy which is going in the right track. This common thing has made the group of countries as an organization providing them a forum where they can communicate the challenges of the world economy. The BRICS has also launched a BRICS New Development Bank to meet the finance requirements for infrastructure development in the developing economies, the need which is now unmet by International Monetary Fund and the World Bank. This can help the BRICS to have a strong influence in the political scenario of the world as well. The BRICS countries are now the major center of attraction for foreign investors also which can further increase their role in the global economy. In terms of GDP, the BRICS has crossed European Union and will sooner cross the GDP share of United States. It is expected that by 2040, the market capital share of around $70 \%$ will be captured by the BRICS economies which suggest that the BRICS will soon be the market leader.

\section{RECOMMENDATIONS}

The BRICS countries should continue their cooperation as a group and avoid any type of conflict that may disturb their performance as a group. The BRICS should continue realizing their need for the South nations to minimize the role and dominance of West in the economic and political scenario of the world. The BRICS should also communicate the challenges faced by other emerging markets other than their members as well as the frontier markets. The BRICS members are also recommended to add other emerging economies in their group also so that they can jointly form a stronger position in the world economy overcoming the strong USA and European Union economy. The BRICS bank should continue providing funds to develop the infrastructure in their countries and the other developing economies to further enhance the economy as good infrastructure plays a key role in the betterment of economy. The BRICS countries should also predict the risk that can emerge in the future and should try to minimize it to avoid any major economic crisis in the world. The BRICS should also focus on resolving the environmental challenges. The BRICS bank should allocate a separate fund for overcoming energy issue as well which is likely to appear as major risk in the near future. In short, the BRICS should work to make the world economy strong by contributing in all quantitative and qualitative manners.

\section{REFERENCES}

[1] O'neill, J. (2001). Building better global economic BRICs.

[2] Piper, L. (2015, April). The BRICS phenomenon: from regional economic leaders to global political players. In Working Paper 3: BRICS Initiative for Critical Agrarian Studies (BICAS) Conference, Cape Town, April..

[3] Ram, P.B. (2015), "BRICS and the Global Economy", Financial Technologies Knowledge Management Company Limited.

[4] De Almeida, P. R. (2009). The Brics' role in the global economy. Cebri-Icone-British Embassy in Brasília: Trade and international negotiations for journalists, 146-154. 
[5] Dhar, B. (2012). The BRICS in the emerging global economic architecture. South African Institute of International Affairs.

[6] Griffith-Jones, S. (2014). A BRICS development bank: a dream coming true? (No. 215). United Nations Conference on Trade and Development.

[7] Biswas, R. (2015). Reshaping the financial architecture for development finance: the new development banks.

[8] Griffith-Jones, S. (2015). Financing global development: the BRICS new development bank. German Development Institute Briefing Paper, 13, 2015.

[9] Cooper, A. F., \& Farooq, A. (2015). Testing the club dynamics of the BRICS: the new development bank from conception to establishment. International Organizations Research Journal, 10(2), 32-44.

[10] Schablitzki, J. (2014). BPC Policy Brief.

[11] Morazán, P., Knoke, I., Knoblauch, D., \& Schäfer, T. (2012). The Role of BRICS in the developing world. Belgium: European Parliament.

[12] Moghadam, R. (2011). New growth drivers for lowincome countries: the role of BRICs. IMF, Strategy, policy and review department, 207.

[13] The Greater Pacific Capital Research (2012), "The Leader India and China Growing Equity Market"

[14] World Economic Outlook (2016), International Monetary Fund.

[15] World Organization For Development (2014), "BRICS Maintain Interest" 